\title{
Is inmunotherapy effective on the treatment of secretory azoospermia?
}

\author{
bo song ${ }^{1}$, mei sun ${ }^{2}$, and weiping qian ${ }^{2}$ \\ ${ }^{1}$ shenzhen Hospital \\ ${ }^{2}$ Affiliation not available
}

May 10, 2021

\begin{abstract}
Aims of the study To assess the effectiveness of medicine and immunotherapy on secretory azoospermia. Methods used to conduct the study The husband with azoospermia was 63 years old and his 35-year-old wife presented secondary infertility for 5 years. The male had operation and chemotherapy of stomach cancer five years ago. After operation and chemotherapy,the male made the treatment on immunotherapy until today. In this treatment, andriol and aescuven forte was given. The total treatment were fourteen months. Semen, blood hormone and pregnancy were detected. Results of the study Six months after treatment, sperm appeared in the semen(2018-12-13:sperm concentration $3 \times 106 / \mathrm{ml}, \mathrm{PR} 0 \%$ ), ICSI was made while ET was failure. 1 year later, the semen was changed greatly (2019-01-29:sperm concentration 43x106/ml,PR 15\%,acrosin 43.1 $\mu \mathrm{IU} / 106)$, second ICSI was made and TET was failed. In May,2020, third cycle ICSI was made,frozen embryo was transplanted in December and in March the wife was conceived for morn than four months. Conclusions We have discussed and published the medicine treatment of azoospermia in 2017 while it is the first time to find the relationship between the spermatogenesis and immunotherapy. Form this case, it could been concluded that Aescuven Forte with Testosterone Undecanoate is good for the patient with testicle dysfunction whhile the time of medicine treatment is better for more than six months. Immunotherapy might be good for spermatogenesis. FSH is a good for ample in the treatment on azoospermia.
\end{abstract}

\section{Hosted file}

_ IJCP-original-article-template.pdf available at https://authorea.com/users/412860/articles/ 521380-is-inmunotherapy-effective-on-the-treatment-of-secretory-azoospermia

\section{Hosted file}

Tabel 1 Follow.pdf available at https://authorea.com/users/412860/articles/521380-isinmunotherapy-effective-on-the-treatment-of-secretory-azoospermia 